\title{
Manpower Development in the Context of Linear \& Non-Linear Dynamic Environment in Arab Countries
}

\author{
Professor Asim Alaraji
}

Dhofar University, Sultanate of Oman; Email: dr_asim39@hotmail.com

Doi:10.5901/mjss.2016.v7n1s1p340

\begin{abstract}
The ongoing globalization, where sharing, cooperating, and exchanging between the North and the South are the major concern of all, has made the transformation from Linear Dynamics to Non- Linear Dynamics present in both developing states of the South and developed states of the North. The above mentioned overall transformation in changes of environmental variables has precipitated serious need for reviewing paradigms and methodologies conventionally used by personnel to deal with their organizational environmental needs. Linear Dynamic approaches of thinking and doing, which are conventionally transmitted to trainees through various programs and plans to guarantee high quality services, are no more enough in the ongoing transformation towards Non- Linear Dynamic changes precipitated mainly by Globalization. Based on the above mentioned points, and due to the fact that various developmental efforts of state members of the South are not realizing their expectations... the following hypothesis is suggested for testing: Non- Linear Dynamic approaches, unlike the conventionally adopted Linear Dynamic approaches, have not been given due emphasis in training and developing personnel in the South. Three main 2006 training plans of three different Arab developing countries (United Arab Emirates, Jordan, and Oman) will be selected as intended sample for testing the above mentioned hypothesis. The analysis findings proved the validity of the research hypothesis. Some suggestions have been developed to give proper weight to the ongoing non-linear environmental dynamic.
\end{abstract}

Keywords: Linear and non-linear dynamic environment, Manpower development, Globalization.

\section{Introduction}

Conventionally universities roles are expressed in three major areas: teaching, research doing and training. The overall objective is to improve human knowledge and skills for better understanding and utilizing the surrounding varieties and dynamism of environmental variables.

Universities training programs, which are the main concern of the present investigation, principally aim at improving personnel knowledge and skills and therefore improving their understanding and manipulation of environmental dynamism surrounding their organizations. Trained personnel are expected to be better equipped for taking relatively viable decisions in their changing environments.

Therefore, designing and planning universities training programs are expected to give proper attention to on-going changes in environmental variables' dynamism of concerned trainees' organizations (Lucas 1998, Wilson 2014, Snell et al. 2015).

Albrecht (2002), Battro (2006), Hellige (2000), McCrone (2000), Storey (2014) and Pink (2005) among others, have pointed out that the overall organizational environmental variables of the present world are shifting from the traditional linear dynamics, where changes are generally incremental, routines, and systematic ,towards non-linear dynamics, where changes are vice versa.

Thus, contemporarily training programs are expected to be continuously readjusting weights given to non-linear dynamics paradigms vis-a-vis the traditional linear dynamics paradigms (Budhwar \& Debrah 2013; Coulson 2004; Hugdahl \& Davidson 2004; Cervero \& Azzaretto, 1990). This could probably help bypassing the expected setbacks in human resources development and consequently, in national development.

Developing countries, including Arab countries, in spite of their continuous efforts to develop their state administrative systems, are still in need for efforts in the same connection (Caiden 1992; Farazmand, 2001). Undoubtedly, designing training programs mainly on linear dynamics paradigms in the present transformation towards globalization, where non-linear dynamics are at raise, could lead to stagnation and lack of progress in human resources development.

Based on the above mentioned points, questions may be raised concerning the viability of the paradigms 
underlying present universities training programs in Arab counties, which still experience number of setbacks in human resources development.

\section{Research Objectives \& Significance}

The major objective of the present investigation is to point out and analyze some premises underling universities training programs in the context of linear dynamics vis-a-vis non-linear dynamic paradigms.

Certain recommendations could probably be developed concerning present weights given to linear dynamics vis-avis non-linear dynamics inclinations so as to improve designing training programs which could have some positive reflections on national development of concerned countries.

\section{Literature Review}

Redesigning training programs so as to better respond to on - going trend towards non-linear dynamics in environmental variables changes has been major concern of number of scholars.

Harden and Laidlw (1992) for example have recommended emphasis on crisis management techniques, contingency approach, flexibility, and spontaneity in designing and in implementing training programs in the present transitional period ot the new world order.

Garrison (1997) calls for designing training programs on what he calls "self directing learning" premise to enable trainees to respond on time to unexpected environmental changes in the present non-linear dynamic world.

Archer et al. (1999) suggest redesigning the overall universities organizational set - ups, including training programs, so as to fit the present world of non-linear dynamics. They point out that the on-going technological changes, which they termed "disruptive technology", are behind the present trend towards nonlinear dynamic environment.

Lauzon (2013) calls for redesigning universities training programs so as to better respond to what he terms the present "Movement towards globalized economy" which is characterized by non - linear dynamism.

Carvero (2001) points out that changes in training programs designs in response to on-going movement in the world towards non-linear dynamism are already taking place during the last twenty years. Increasing multiplicity and variety of training programs through the surveyed period are probably some of the indicators.

Baumgartner (2001) suggests incorporating what he calls "transformative learning" premise in designing training programs in the non - linear dynamic environment. In other words, he states that non - linear dynamics world need personnel who are "change - agents" in the first place.

Cranton (2003) emphasizes the needs for training people to be "transformative learner" too. He also emphasizes the importance of increasing the varieties and multiplicities of training programs in response to the present trend towards non - linear dynamic environment.

Although findings of the literature have been tested in developed countries environmental context, they could be of certain validity for designing training programs in developing countries, including Arab countries since they share the rest of the world the ongoing transformation towards Globalization (Welch \& Wong, 1998; Farazmand, 2008).

\subsection{Research Hypothesis}

It is hypothesized that Arab universities are not giving proper emphasis to nonlinear dynamic paradigms vis-a-vis the traditional linear dynamic paradigms in designing and in implementing their training programs.

\subsection{Research Sample}

Three Arab universities training plans of 2006 were chosen for testing the research hypothesis due to their major roles in their concerned countries besides their accessibility. They were: the Jordanian university (JU) training plan, the United Arab Emirates universities (UAEU) training plan, and the public administration institute (PAI) training plan (which is under direct supervision of Sultan Qabos University in Oman).

After screening out activities which are not training programs, the remaining training programs in the three surveyed training plans are: JU (37), PAI (71), and UAEU (36). 


\subsection{Research Methodology}

Due to certain limitations in accessing some needed field information the following indicators are indicated from related literature for diagnosing and comparing inclinations of the training programs towards linear vis-à-vis non-linear dynamic paradigms.

With regard to "varieties of training programs objectives" (Corvero, 2001; Baumgarter, 2002) it is stated that the lager the varieties of training programs objectives the more the training plans inclination towards non-linear dynamic paradigms.

In the same connection, it is stated that the more the duplications of training programs objectives in a training plan the more it is inclined towards linear dynamics paradigms (Lauzon, 2013).

2. In terms of the "multiplicity of training programs" (Cervero, 2001) it is found that the larger the multiplicity of training programs through a given period of time the more the training plan inclination towards on - linear dynamics paradigms.

3. Number of suggested job behavioral modification alternatives included in a single training program (Archer et.al., 1999; Lauzon, 2013): it is proposed that the larger the number of job behavioral modification alternatives offered to trainees in a single training program the greater the responsiveness of the training plan to the nonlinear changes of environmental variables dynamism.

4. Emphasis on "self-directed learning" in a training program (Harden \& Laidlaw, 1992; Garrison, 1997): it is stated that the greater the emphasis in training programs on promoting "self - directed learning" the greater the training plan responsiveness to the non - linear changes of the environmental variables dynamism.

In the same connection, it is proposed that the greater the emphasis on "contingency approach" in training programs the greater the training plan responsiveness to non - linear changes in environmental variables dynamism.

5. The continuity and renewal of training programs (Corvero, 2001, 1990): It is propsed that the greater the renewal of training programs objectives the greater the responsiveness of the training plan to non - linear changes of environmental variables dynamism.

6. Promoting "transformative learning" (Baumgartner, 2001): it is proposed that the greater the emphasis on promoting transformative learning" in training programs the greater the training plan responsiveness to the on - going trend towards non - linear changes in environmental variables and dynamism.

\subsection{An overall analysis of the training plans inclinations:}

Based on the six indicators cited above, the overall inclinations towards linear dynamics or non - linear dynamics paradigms of the surveyed three training plans can probably be diagnosed as follow:

- With regard to "varieties of training programs objectives" (Corvero, 2001; Cranton, 2003; Baumgartner, 2001), the PAI plan contains (59) different training objectives while each of the JU and UAEU plans contains only (20) different objectives. Therefore, PAI training plan is relatively more inclined towards non-linear dynamics paradigms than the other two plans.

It terms of "duplication of training programs goals" indictor, it is found that PAI, plan has (12) duplications (16.9\%), the UAEU plan had (16) duplication (33.3\%), and the JU plan has (17) duplication (45.9\%). This means that PAI plan is more inclined towards non -linear dynamics paradigms than the other two.

- In terms of multiplicity of training programs in the three training plans during 2006 Table 2 show that PAI plan contains (71) training programs while UAEU plan contains only (36) and JU plan contains (37) during 2006. This means that PAI plan is more responsive to the on - going non - linear dynamism of globalization than the other two plans if other local training institutions roles are overlooked.

- In terms of "number of job behavioral modification alternatives" in a single training program" (Archer et.al. 1999; Lauzon 2013) it is found, through reviewing contents of training programs of the three plans and through interviewing number of concerned trainers that numbers of job behavioral modification alternatives are usually limited to one or two in any single training program in each of the three plans. This indicates an overwhelming inclination towards linear dynamics paradigms. Reasons for the limited job behavioral modification alternatives, as expressed by interviewed trainers, are time limitation and lack of needed technical and educational capabilities of trainees in comparing and in selecting among behavioral alternatives.

In terms of the "contingency approach" (Harden \& Laidlaw 1992) it is found that very limited emphasis is given to this indicator in the three surveyed plans. It is observed that on extra emphasis is given by concerned 
training leaderships to formality in designing and in implementing training plans in the three cases.

- With regard to "self - directed learning" (Harden \& Laidlaw, 1992; Garrison, 1997), it is found, through analyzing objectives and contents of concerned training programs of the surveyed three training plans, that there is very limited emphasis on this indicator. Inculcation and indoctrination are the preferred training methodology in implementing the surveyed plans. This makes inclination towards linear dynamic paradigms predominant. Reason for the limited emphasis on the "self - directed learning" is probably the poor heterogeneity of trainees' educational background.

- With regard to "duration and renewal of training programs (Corvero, 2001), it is found that the three institutions whose training plans are subjected to the present analysis, had started designing training programs since more than ten years. This means that training plans almost on the same footing with regard to inclination towards non-linear dynamic paradigms.

- In terms of promoting "transformative learning" through training programs (Baumgarrwner, 2002; Cranton, 2003) it is found through context analysis, that the surveyed training programs tends to promote "no transformation" instead of "continuous transformation".

Therefore, the overall inclinations of the surveyed three, training plans are in favor of the linear dynamics paradigms.

\subsection{Detail Analysis of the Three Training Plans:}

Each of the training programs in every one of the three surveyed plans has been independently categorized according to its inclination towards linear and non-linear dynamics paradigms based on the same six indicators as illustrated in Table 1.

Table 1: Numbers \& Percentages of Training Programs According to their Inclination towards Linear \& Non-Leaner Dynamics Paradigms

\begin{tabular}{|l|c|c|c|c|c|c|}
\hline Training plans 2006 & Linear dynamics inclination & \multicolumn{2}{|c|}{ Parallel linear \& Non - Linear Dynamics Inclination } & \multicolumn{2}{|c|}{ Non-Linear Dynamics Inclination } \\
\hline PAI. Plan & 40 & $56 \%$ & 27 & $39 \%$ & 4 & $5.6 \%$ \\
\hline UAEU. Plan & 21 & $58 \%$ & 11 & $30.5 \%$ & 4 & $11 \%$ \\
\hline JU. Plan & 10 & $27 \%$ & 15 & $40.5 \%$ & 12 & $32.4 \%$ \\
\hline
\end{tabular}

Table 1 points out that (40) programs (56\%) in the PAI plan, (21) programs (58\%) in the UAEU plan an (10) programs $(27 \%)$ in the JU plan inclined towards linear dynamics paradigms.

On the other side, (4) programs (5.6\%) of the PAI plan (4) programs (11\%) of the UAEU plan and (12) programs of the $\mathrm{JU}$ plan are inclined towards non-linear dynamics paradigms.

Meanwhile, the same table points out that (27) programs (39\%) of the PAI plan (11) programs $(30.5 \%)$ of the UAEU plan, and (15) programs (40.5\%) of the JU plan show parallel linear and non-linear dynamics inclination.

If this parallel inclination understood as transition from the traditional linear dynamics paradigms towards the contemporary non-linear dynamics paradigms, it can be said that the validity of the research hypothesis is decreasing.

Based on the same six indicators, levels of inclinations of training programs are measured and categorized in terms of number of hours assigned to each category as illustrated in Table 2.

Table 2: Levels of Training Programs Inclinations towards Linear and Non-Leaner Dynamics Paradigms in Terms of Training Hours

\begin{tabular}{|c|c|c|c|c|c|c|}
\hline Training plans 2006 & Linear dynamics inclination & Parallel linear \& Non - Linear Dynamics Inclination & \multicolumn{2}{|c|}{ Non-Linear Dynamics Inclination } \\
\hline PAl. Plan & 1320 & $70.4 \%$ & 490 & $26 \%$ & 65 & $3.4 \%$ \\
\hline UAEU. Plan & 420 & $59.15 \%$ & 220 & $30.9 \%$ & 70 & $9.8 \%$ \\
\hline JU. Plan & 270 & $28.4 \%$ & 358 & $37.3 \%$ & 320 & $33.7 \%$ \\
\hline
\end{tabular}

Table 2 shows that (1320) hours (70.4\%) of the total PAI. Training hours (420) hours (59.15\%) of the total UAEU training hours, and (270) hours (28.4\%) of the total JU training hours are devoted to promote linear dynamics inclination.

On the other side the same table shows that (65) hours (3.4\%) of the total PAl training hours, (70) hours (9/8) of the total UAEU training hours, and (320) hours (33.7\%) of the total JU training hours are devoted to promote non-linear 
dynamics inclination.

Levels of parallel inclinations towards linear and non-linear dynamics paradigms of training programs are (49\%) hours (26\%) in the PAI plan, (220) hours (30.9\%) in the UAEU plan and (358) hours (37.7\%) in the JU plan

Here too, levels of parallel inclinations could mean transition from the traditional linear inclination towards the contemporary non-linear inclination. This means that the validity of the research hypothesis is decreasing.

\section{Conclusion \& Recommendations:}

Persisting emphasis on linear dynamics paradigms in the surveyed training plans could probably be rationalized on the bases that developing countries, including Arab countries, are still in process of building their institutionally.

Never the less, the undue extra emphasis given to linear dynamics paradigms vis-à-vis non-linear dynamics paradigms could lead to a limited progress in human resources development, and consequently to a limited administrative and national development. Percentages of parallel inclination towards linear \& non-linear dynamics paradigms in the training programs of the three plans could hopefully lead to readjusting the present weights given to linear vis-à-vis non-linear dynamics paradigms so as to respond better to globalization imperatives.

Based on these findings, it is recommended that the six indicators, deducted from related literature (Archer et.al., 1999; Corvero, 2001, 1990; Cranton, 2003; Carrison, 197; Lauzon, 2013; Baumgartner, 2001; Harden \& Laidlaw, 1992) could be of contain benefit for re-designing universities training plans and programs in the presents globalization age. It is recommended too that additional training plans in other Arab countries could be included in following research projects for the same purpose.

Analyzing historical changes in training plans in the context of linear and non-linear dynamics paradigms could be of certain benefits too.

\section{References}

Albrecht, K. (2002). Brain power. Training \& Development, 56 (11), 38-46.

Archer, W., Anderson, T., \& Garrison, R. (1999). Adopting Disruptive Technologies In Traditional Universities: Continuing Education As An Incubator For Innovation. Canadian Journal of University Continuing Education, 25(1), 13-30.

Battro, A. M. (2006). Half a brain is enough: The story of Nico (Vol. 5). Cambridge University Press.

Baumgartner, L. M. (2001). An update on transformational learning. New directions for adult and continuing education, 2001(89), 15-24.

Budhwar, P. S., \& Debrah, Y. A. (Eds.). (2013). Human resource management in developing countries. Routledge.

Caiden, G. E. (1992). Administrative reform comes of age. Public administration, 70, 137.

Cervero, R. M. (2001). Continuing professional education in transition, 1981? 2000. International Journal of Lifelong Education, 20(1-2), 16-30.

Cervero, R. M., \& Azzaretto, J. F. (1990). Visions for the future of continuing professional education. University of Georgia Center for.

Coulson, S., \& Lovett, C. (2004). Handedness, hemispheric asymmetries, and joke comprehension. Cognitive Brain Research, 19(3), 275-288.

Cranton, P., \& King, K. P. (2003). Transformative learning as a professional development goal. New directions for adult and continuing education, 2003(98), 31-38.

Farazmand, A. (Ed.). (2001). Handbook of Comparative and Development Public Administration. CRC Press.

Farazmand, A. (2008). Globalization and Public Administration. Public Administration Review, 59(6).

Garrison, D. R. (1997). Self-directed learning: Toward a comprehensive model.Adult Education Quarterly, 48(1), 18-33.

Harden, R. M., \& Laidlaw, J. M. (1992). Effective continuing education: the CRISIS criteria. Medical Education, 26(5), 407-422.

Hellige, J. B. (2000). All the king's horses and all the king's men: Putting the brain back together again. Brain and cognition, 42(1), 7-9.

Hugdahl, K., \& Davidson, R. J. (2004). The asymmetrical brain. MIT Press.

Lauzon, A. C. (2013). University extension and public service in the age of economic globalization: A response to Thompson and Lamble. Canadian Journal of University Continuing Education, 26(1).

Lucas, C. J. (1998). Crisis in the academy: Rethinking higher education in America. Palgrave Macmillan.

McCrone, J. (2000). Right Brain" or "Left Brain" Myth or Reality. The New Scientist.

Pink, D. H. (2005). A Whole New Mind: Moving from the information age into the conceptual age. Riverhead.

Snell, S., Morris, S., \& Bohlander, G. (2015). Managing human resources. Cengage Learning.

Storey, J. (2014). New Perspectives on Human Resource Management (Routledge Revivals). Routledge.

Welch, E., \& Wong, W. (1998). Public administration in a global context: bridging the gaps of theory and practice between western and non-western nations. Public Administration Review, 40-49.

Wilson, J. P. (2014). International human resource development: Learning, education and training for individuals and organisations. Development and Learning in Organizations, 28(2). 